\title{
Butterfly diversity and seasonality of Ta Phin mountain area (N. Vietnam, Lao Cai province)
}

\author{
Markus Franzén ${ }^{1,2} \cdot$ Julian Schrader $^{3}$ - Göran Sjöberg ${ }^{4}$
}

Received: 30 August 2016 / Accepted: 26 April 2017 / Published online: 13 May 2017

(C) The Author(s) 2017. This article is an open access publication

\begin{abstract}
Human pressures on the environment are changing spatially and temporally, with profound implications for the planet's biodiversity. Butterflies are important indicators for environmental change and are a suitable group to detect areas of high conservation concern and prioritize conservation efforts. To obtain data to support urgently-needed conservation measures, we surveyed the butterfly fauna in a mountainous region of northern Vietnam, using transect counts over 8 months (121 survey days) from June 2014 to April 2015. In total, we recorded $>26,000$ butterflies belonging to 231 species, including at least two species new to Vietnam, three red-listed and protected species listed by CITES. Most species were rare: we recorded members of 100 species $\leq 5$ times and 52 species just once. Males dominated the sample, accounting for $81 \%$ of all observed butterflies and all members of 84 observed species. Species richness and abundance were
\end{abstract}

Electronic supplementary material The online version of this article (doi:10.1007/s10841-017-9985-z) contains supplementary material, which is available to authorized users.

Markus Franzén

Markus.franzen@lnu.se

1 Department of Biology and Environmental Science, Center for Ecology and Evolution in Microbial Model Systems, EEMiS, Linnaeus University, 39182 Kalmar, Sweden

2 Department of Community Ecology, UFZ Helmholtz Centre for Environmental Research, Theodor-Lieser-Str. 4, 06120 Halle, Germany

3 Department of Biodiversity, Macroecology and Biogeography, Faculty for Forestry and Forest Ecology, University of Goettingen, Büsgenweg 1, 37077 Goettingen, Germany

4 Avellaneda Museum, Furängsvägen 56, 80598 Gävle, Sweden highest in July, and there were surprisingly large changes in species composition between months. Species richness curves reached saturation, indicating that we detected most species present in the area, except for members of two families (Lycaenidae and Hesperiidae). Our results highlight the importance of thorough studies using standardized methods, capable of detecting most species in an area, over a whole season. There are urgent needs to integrate butterflies into conservation programs and use their potential as indicator species of habitat degradation and land use intensity.

Keywords Conservation - Environmental change · Disturbance $\cdot$ Monitoring $\cdot$ Montane forest

\section{Introduction}

Anthropogenic environmental pressures driven by intensification of human land use and global climate change are changing many natural habitats (Tilman et al. 2001; Root et al. 2003). The rate of change is especially high in South East Asia (Sodhi et al. 2004; Venter et al. 2016), a region which harbours numerous endemic species and biodiversity hotspots (Myers et al. 2000; Laurance et al. 2011). However, despite their global importance and threats they face, few ecosystems in South East Asia and other tropical regions have been surveyed sufficiently intensively to formulate detailed conservation plans (Koh 2007).

Butterflies are sensitive to environmental pressures and thus highly suitable for monitoring the health and diversity of ecosystems, and detecting indications of environmental change (Hayes et al. 2009; Bonebrake et al. 2010). Furthermore, their taxonomy is relatively well known in comparison with other tropical insect groups, and data on 
the geographic distributions and life histories of some species are available (Spitzer et al. 1993, 1997; New 1997; Suguru and Haruo 1997, 2000). A complicating factor is that seasonality of insects has been observed in all parts of the world, including the equatorial tropics. Thus, surveys should ideally cover many months to detect such seasonality, and taxa that may be missed by shorter surveys (Wolda 1988). However, few datasets allowing analysis of the full diversity and seasonality of particular taxa, especially in South East Asia, are available (Vu and Vu 2015). Earlier studies in this region have focused on taxonomy or the habitat preferences of butterflies, and were often based on material collected over a short period of time with a focus on specific butterfly families (Spitzer et al. 1993, 1997; Monastyrskii 2007a; Vu et al. 2015).

Sampling approaches used in ecological studies on butterflies vary greatly, especially in parts of the tropics where identification of species is problematic. Seasonality is often ignored and many studies rely on a limited field effort with long periods between the visits (Spitzer et al. 1993; Walpole and Sheldon 1999; Vu et al. 2015). Sometimes samples are collected at regular intervals (once per month or per week), sometimes only on warm days, and sometimes irrespective of temperature and weather conditions (Walpole and Sheldon 1999). For butterflies in subtropical or tropical regions there are no strict criteria concerning suitable conditions for monitoring butterflies, such as those available for temperate regions (Pollard 1977). In the study area, as in the tropics generally, daily rain, moderate temperatures and high humidity make butterfly surveys very challenging. Many species are also difficult to identify solely on the basis of transect observations (Walpole and Sheldon 1999).

In this study, we focus on the butterfly community in a mountainous area in northern Vietnam which is in urgent need of butterfly conservation research since (as in the rest of South East Asia) natural habitats are disappearing at alarming rates (Koh 2007; Venter et al. 2016). Mountain forests bordering a tropical zone are particularly interesting in terms of diversity and seasonality as they include species from lower latitudes without pronounced seasonality, species from higher latitudes with seasonality induced by environmental variation, and species with seasonal behaviour associated with their evolutionary history (particularly species originating from temperate monsoon environments) (Monastyrskii 2007a). This study had four main aims; (a) to describe the species composition of the butterfly community in the study area, (b) to assess current knowledge of the region's butterfly fauna, (c) to explore variations in seasonality among the butterfly taxa and (d) to provide data (including pictures of all observed species together with information about their abundance and ecological determinants) to contribute to a comprehensive database of tropical
Indochinese butterfly communities that could facilitate their future conservation.

\section{Materials and methods}

\section{Study area}

The surveys were performed along a $10 \mathrm{~km}$ long transect (ranging in altitude from 1200-1700 m) in the surroundings of Ta Phin (latitude $22.397^{\circ} \mathrm{N}$, longitude $103.842^{\circ} \mathrm{E}$ ), a small village with about 300 inhabitants (in 2014-2015) located in Lao Cai province, northern Vietnam, $380 \mathrm{~km}$ north-west of Hanoi and $17 \mathrm{~km}$ south of the Chinese border (Fig. 1). Part of the study area is situated in Hoàng Liên National Park. The area hosts diverse habitat types, including secondary montane laurel forest (30\%), forest clearings $(10 \%)$ and anthropogenic habitats such as secondary grassland $(10 \%)$, rice fields $(10 \%)$, shrub land $(15 \%)$, cultivated areas (20\%), and built-up areas (5\%) (data from field visits in 2014 and 2015 and SPOT-5 satellite images from 2012). This type of land cover is typical of the general landscape in northern Vietnam and neighbouring areas in China. The area is biogeographically interesting because it is situated in a mountain range dividing the tropics and the subtropicsa zone in which tropical, subtropical and northern temperate species co-occur (Stott 1991; Bozano et al. 2016). The Hoàng Liên Son mountains are a small mountainous ridge in northern Vietnam forming the eastern extremity of the Himalayas (Fig. 1), covered by mixed landscapes of secondary forests and more disturbed areas and rice fields. The butterfly fauna in the region is known to be rich, comprising more than 300 species, excluding Lycaenidae (Hill and Monastyrskii 1999; Monastyrskii and Devyatkin 2015), many of which are highly abundant (Monastyrskii 2007a; $\mathrm{Vu}$ et al. 2015). The climate has pronounced seasons with rainy summers influenced by the monsoon (May-August), and foggy, cold winters with occasional snowfall (Fig. 2a, b). The forest is typical of laurel forests with a high diversity of tree and shrub species (mainly of the families: Aceraceae, Cupressaceae, Ericaceae, Fagaceae, Juglandaceae, Lauraceae, Magnoliaceae, and Pinaceae) (Thin and Harder 1996; Averyanov et al. 2003). Human influences are apparent both in the surroundings of Ta Phin village and Hoàng Liên National Park generally, with degrees of disturbance ranging from ruderal vegetation to agroecosystems in proximity to secondary forests. There are no undisturbed habitats in the study area.

\section{Data collection}

Intensive regular sampling was carried out between 3rd June-3rd November 2014 and 15th March-4th April 

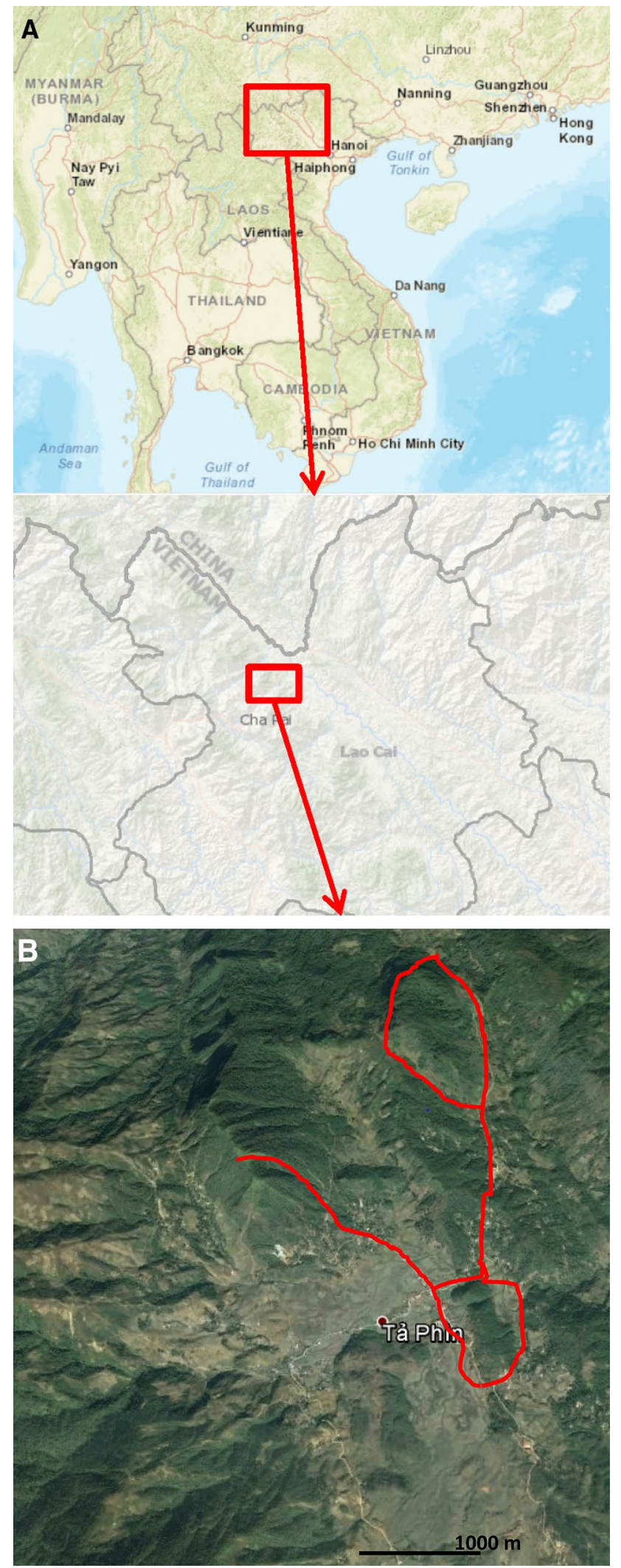

Fig. 1 Location of Ta Phin village and the butterfly transect in northern Vietnam. Maps with permission from ${ }^{{ }} 2016$ Google image, CNES/Astrum

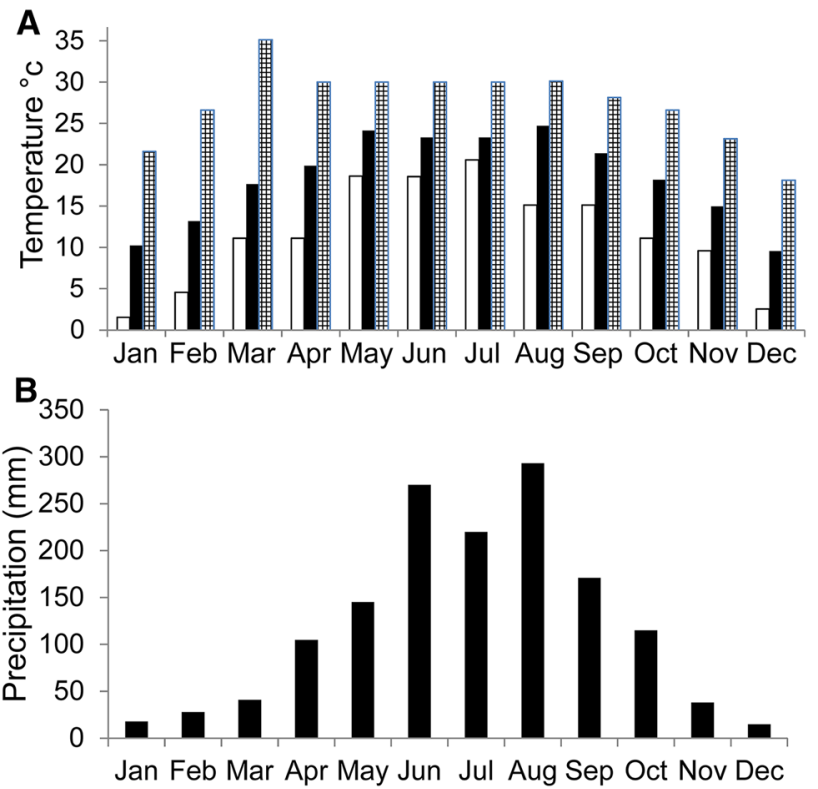

Fig. 2 a Climate data from Ta Phin 2014-06-01 to 2015-05-31. The filled bars represent daily average temperatures; checked bars show average daily maximum temperatures; empty bars show average daily minimum temperatures averaged for respective month. b Precipitation data (based on monthly average data from 2000 to 2010) from the nearest weather station in Sapa, $15 \mathrm{~km}$ north of the study area

2015. During these periods, the weather was suitable for butterfly surveys on 121 days ( 21 in June, 25 in July, 13 in August, 22 in September, 21 in October, 2 in November, 15 in March and 3 in April). Butterflies were studied using a modified transect method (Pollard 1977; Spitzer et al. 1993, 1997). Three teams of two observers walked together along approximately $3 \mathrm{~km}$ long segments of a transect extending over $10 \mathrm{~km}$ in total (Fig. 1), at a speed of approximately $100 \mathrm{~m}$ per $10 \mathrm{~min}$. During the walk, they recorded all butterflies seen (Fig. 3a-c) in a belt approximately $20-40 \mathrm{~m}$ wide. The transect was walked during days with favourable weather conditions between the hours of 8 am and $4 \mathrm{pm}$, at temperatures $<15^{\circ} \mathrm{C}$ with some sunshine $(<80 \%$ cloud cover). The transect was located along paths and small roads. At points where large butterfly aggregations occurred, e.g. where butterflies were searching for food or minerals, longer stops were required to count and identify all butterflies present.

We collected daily temperature data using an iButton data logger (model DS1922L), accurate to $0.4{ }^{\circ} \mathrm{C}$, which was placed in Ta Phin village at a height of $120 \mathrm{~cm}$ in shade from June 12014 through to May 31 2015. Temperature data were logged every $10 \mathrm{~min}$. Precipitation data (based on monthly average data from 2000 to 2010) was extracted from the nearest weather station in Sapa, $15 \mathrm{~km}$ north of the study area. 

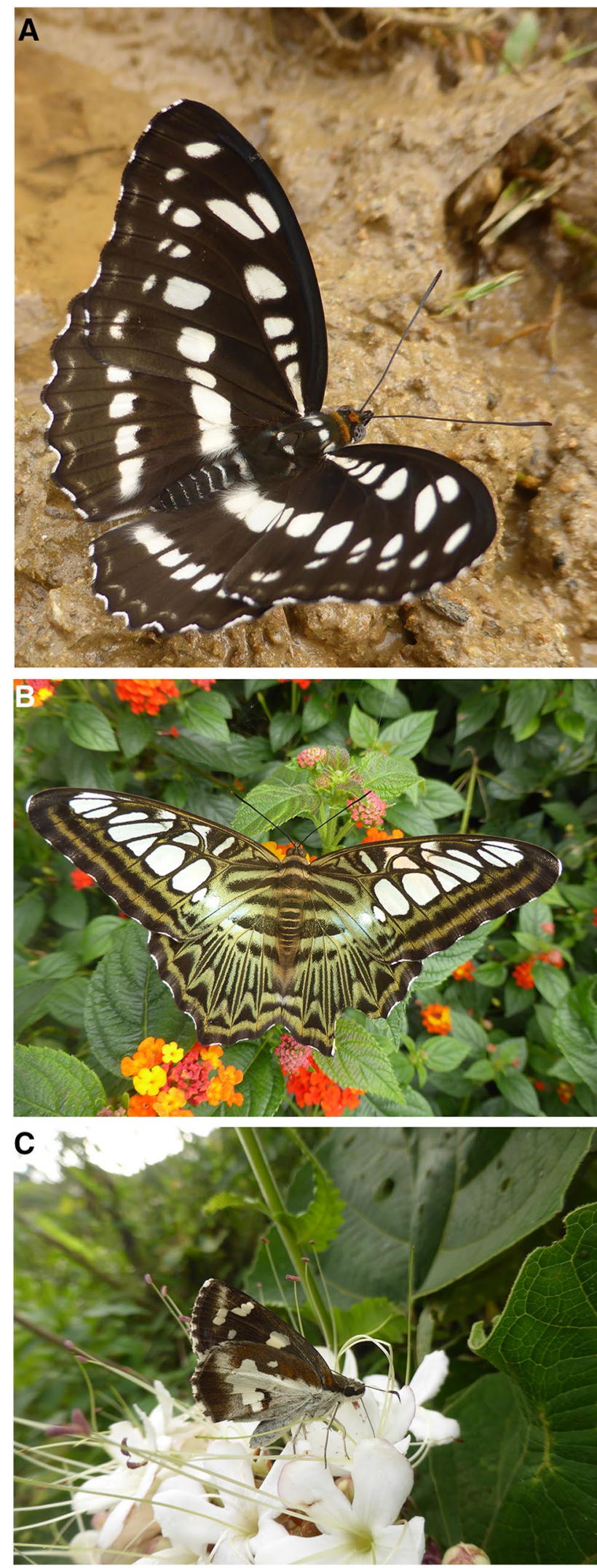

Fig. 3 Examples of three butterflies occurring in the study area. a Athyma perius (Nymphalidae), b Parthenos sylvia (Nymphalidae) and c Udaspes folus (Hesperiidae)

\section{Butterfly identification}

Since 2000, the knowledge of the Vietnamese butterfly fauna has increased dramatically (Uehara and Yokochi 2001; Morita 2002, 2003; Seki and Saito 2006; Yokochi 2010, 2011, 2012; Nakamura 2014). Thus, for a correct identification it is impossible to rely on older identification books (D' Abrera 1982; Chou 1994) and the butterfly fauna in Vietnam has increased with over 15 species per year from 2003 to 2015 (Monastyrskii and Devyatkin 2003, 2015). This has been the result from a number of recent field investigations, taxonomic revisions and book projects (Monastyrskii 2005, 2007b, 2011; Bozano et al. 2016).

In northern Vietnam, it is difficult to record and identify butterfly species without catching them. Even among the largest species it is difficult to identify species correctly without closer inspection. For example, Papilio helenus may be easily confused with $P$. nephelus, $P$. memnon with P. protenor, P. doddsi with P. bianor, Graphium mandarinus with G. eurous, G. doson with G. evemon, G. leechi with G. chironides. Taxonomically complicated genera such as Euthalia, Mycalesis, Ypthima, and Neptis often require that specimens are collected for further examination. To identify and determine the sex, all individuals reported in this study were captured with a butterfly net. Butterflies high up in trees and shrubs were also caught with a long butterfly net. Species that could not be identified in the field were either photographed and released or collected for later identification. We also created a reference collection of voucher specimens from the area to improve the accuracy of identification in the field and to facilitate future taxonomic revisions (Online Resource 2). We have followed the taxonomy and systematics according to Monastyrskii and Devyatkin (2015) except for Kallima limborgi that follows Küppers (2015).

\section{Data analysis}

To study seasonal patterns, we analysed changes in the butterfly community between consecutive months. As a measure of monthly species turnover two types of incidence-based (dis)similarity indices were calculated: the Jaccard index and a modified version of the Simpson index (Petanidou,et al. 2008). Both indices range from 0 to 1 , where 1 equals $100 \%$ similarity. The Jaccard index is calculated as:

$j=\frac{a}{a+b+c}$

where $a$ is the number of "shared" species recorded in two consecutive months, while $b$ and $c$ are the numbers of unique species recorded in each month (thus the index is the number of shared species divided by total species 
richness). The modified Simpson index is calculated by dividing the number of shared species by the number of species recorded in the month with the lowest number of species $(d)$ :

$S=\frac{a}{d}$.

Thus, this index distinguishes between changes in species richness and changes in species turnover (Koleff et al. 2003). For example, 96 species were detected in March and April, of which 20 were unique to March, 17 were unique to April and 59 were recorded in both months. The resulting Jaccard index is 0.61 , indicating substantial compositional similarity, while the modified Simpson index is higher $(0.78)$ because the large difference in number of species between months does not affect the outcome.

We estimated the species richness of each family based on the daily samples using first-order jackknife, a nonparametric resampling method using the software EstimateS 9.1.0 (Colwell 2013). To explore fluctuations in species' numbers we calculated coefficients of variation (CV) from the daily catch data, by dividing mean numbers $(\mu)$ with the corresponding standard deviations $(\sigma)$.

\section{Results}

In total, we observed 26,332 butterflies belonging to 231 species. Most of the species found (123) belong to the Nymphalidae family (Table 1, Online Resource 1,2). The three most abundant species were Euploea mulciber followed by Pachliopta aristolochiae and Papilio protenor, all of which were observed more than 2500 times. The species recorded on most days ( $>90)$ was Papilio protenor, followed by Euploea mulciber and Papilio bianor (Online Resource 1). At least two species, Euthalia monbeigi and $E$. masaokai were never recorded in Vietnam before. Small numbers of most species were recorded, including 52 only once and 100 species $\leq 5$ times (Online Resource 1). Males dominated, accounting for $81 \%$ of all the butterflies observed, and all members of 84 recorded species, including some abundant species such as Polyura dolon, Zemeros flegyas, Lethe confuse, Lethe sinorix, and Cyrestis thyodamas (Online Resource 1).

\section{Seasonality}

On average 29 species were observed per day, but this number varied substantially (Fig. 4a, Online Resource 1). The numbers were highest in late July and late September, peaking at 77 species on September 19. The most species-rich months were July and September (when we observed 147 and 143 species, respectively) and the least species-rich months were November and April (31 and 79 species, respectively). Butterfly abundance displayed a similar pattern to species richness, with the number of observed individuals peaking (at 1064) on 1 September (Fig. 4b, Online Resource 1). As shown in Fig. 5, July and September were also the months in which the largest percentages of species peaked in abundance (24 and $20 \%$, respectively, compared to $9-15 \%$ in the other months). Only 15 species were found in all of the eight survey months (Online Resource 1). The similarity indices showed that there were surprisingly large changes in species composition over time; the Jaccard index ranged from 0.26 to 0.62 between consecutive months, and the modified Simpson index from 0.58 to 0.97 (Fig. 6). Numbers of many species fluctuated strongly between days; Lamproptera curius, Papilio doddsi, Vanessa indica, Athyma cama, and Hestina assimilis most dramatically (Online Resource 1). The species richness estimates indicated that we found most species in the study area, except members of the two families Lycaenidae and Hesperiidae (Table 1; Fig. 7).
Table 1 Numbers of species and individuals recorded, by family

\begin{tabular}{lccccc}
\hline Family & $\begin{array}{l}\text { No. of species } \\
\text { recorded from } \\
\text { Vietnam }^{\mathrm{a}}\end{array}$ & $\begin{array}{l}\text { No. of species recorded } \\
\text { from northern Vietnam }\end{array}$ & $\begin{array}{l}\text { a } \\
\text { fies in this } \\
\text { study }\end{array}$ & No. of individuals & $\begin{array}{l}\text { No. of } \\
\text { single- } \\
\text { tons }\end{array}$ \\
\hline Papilionidae & 69 & 59 & 36 & 11,989 & 2 \\
Pieridae & 57 & 47 & 27 & 1067 & 6 \\
Nymphalidae & 418 & 317 & 122 & 13,050 & 23 \\
Riodinidae & 31 & 18 & 6 & 84 & 1 \\
Lycaenidae & 318 & 160 & 22 & 67 & 9 \\
Hesperiidae & 288 & 193 & 18 & 75 & 11 \\
Total & 1181 & 794 & 231 & 26,332 & 52 \\
\hline
\end{tabular}

${ }^{a}$ According to Monastyrskii and Devyatkin (2015) 

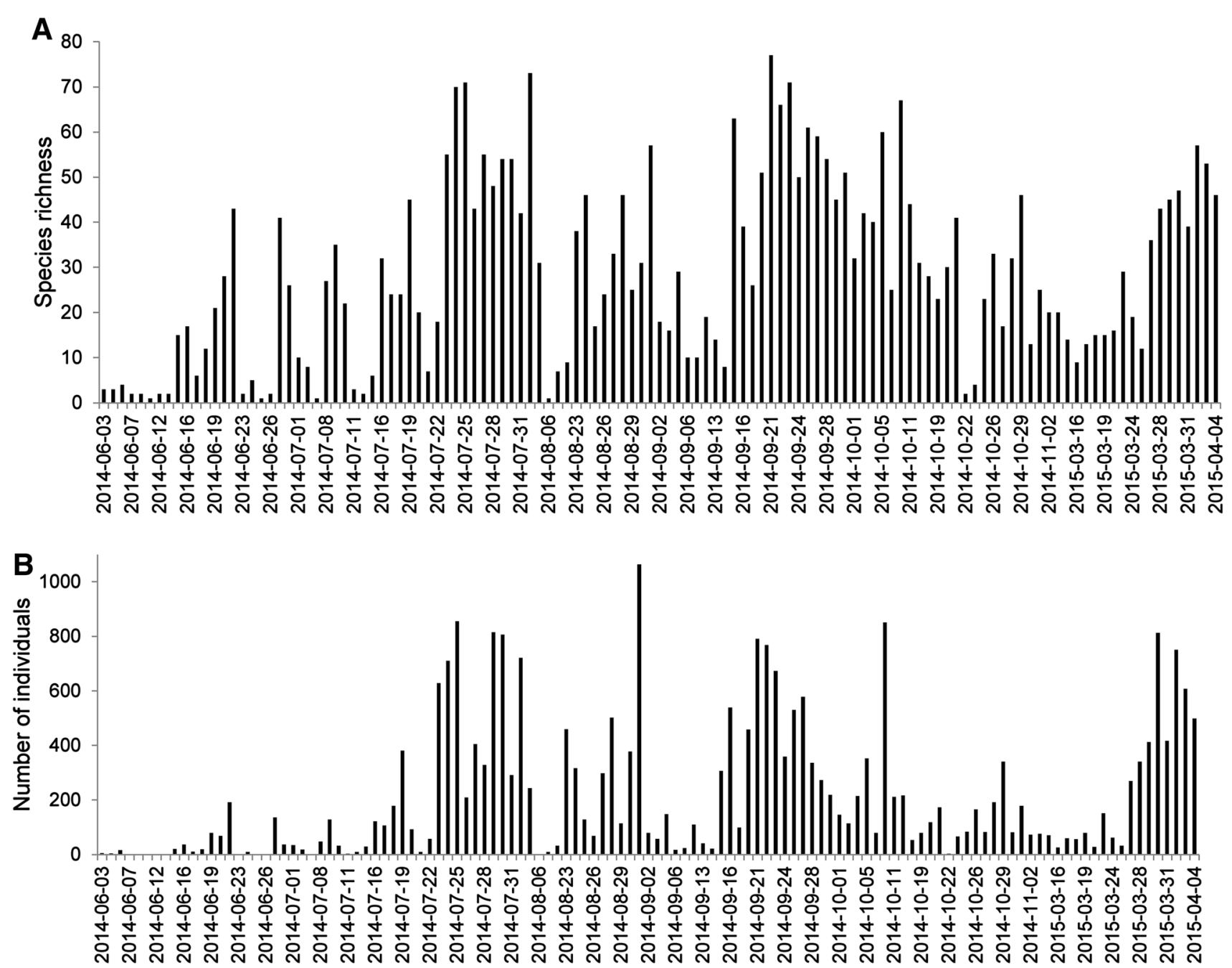

Fig. 4 Daily observations of butterfly species (a) and individuals (b). Observe that dates are from 3 June 2014 to 4 April 2015 in chronological order

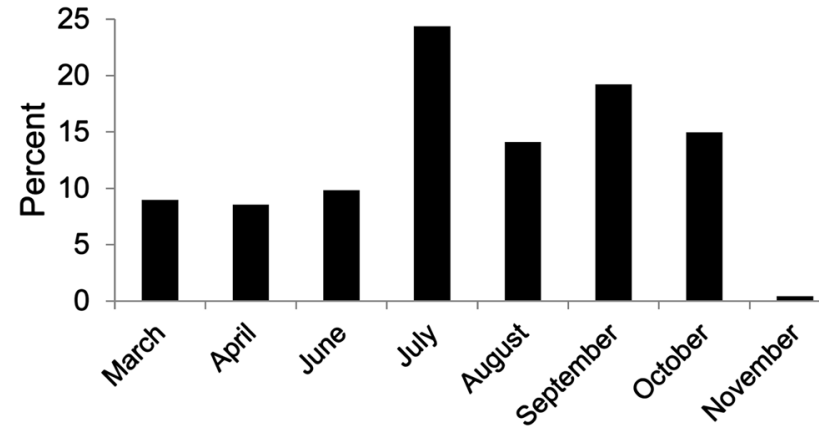

Fig. 5 Proportion of species that peaked in abundance in each survey month

\section{Discussion}

Our survey of butterflies in a mountainous area of northern Vietnam (spanning eight months in total) detected clear signs of seasonality in the butterfly fauna, with species richness peaking in late July and late September. Our data also show that males are more readily observed than females, and there are large daily fluctuations in the abundance of butterflies (visually observable), especially for some species. We also detected a surprisingly high diversity of butterflies in the region and intensive sampling efforts are required to detect all species in an area, especially members of the families Hesperiidae and Lycaenidae. Our study is one of few that present reliable abundance data collected over many months in a small area, enabling analysis of seasonality patterns in a butterfly community in Indochina. Butterflies have been studied in several areas of northern Vietnam, particularly Tam Dao National Park (Spitzer et al. 1993; Vu 2009; Vu et al. 2015). However, no previous study to our knowledge has examined the butterfly fauna in a limited area so intensively or over nearly a complete year. Indeed, our study shows such striking 


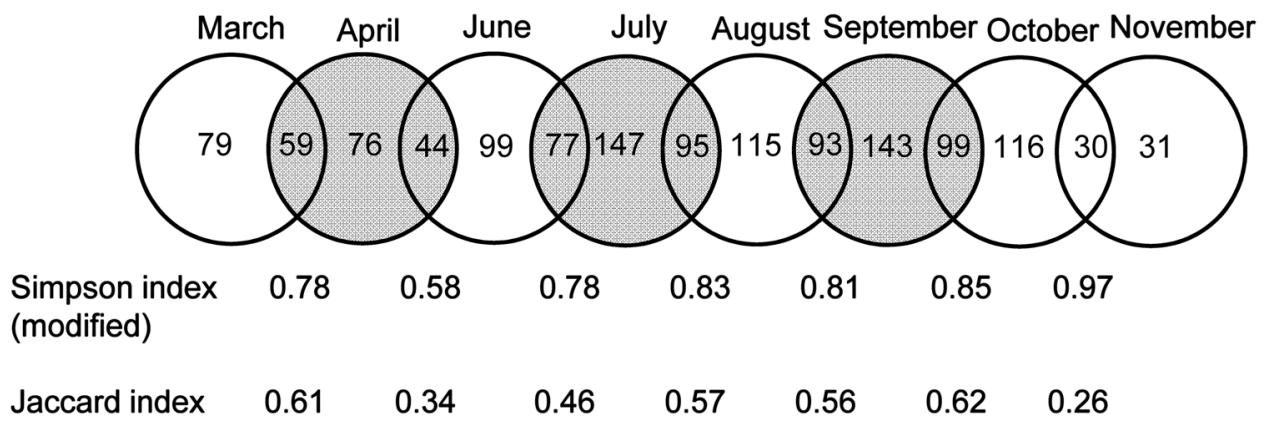

Fig. 6 Number of species observed in each month, and number of species shared between consecutive months (except April-June, because there were no observations in May). The Jaccard and Simp-

son indices reflect similarities in species composition and species richness, respectively. The total number of species recorded was 231
Fig. 7 Jackknife species richness estimates (first order) for each butterfly family. Dotted line (......) (Nymphalidae), dashed line (- -) (Papilionidae), dashed line (.- .-) (Pieridae), blue/grey (Lycaenidae), red dashed line $(--\cdots \ldots$.. $\cdots)$ (Hesperiidae) and black (Riodinidae). (Color figure online)

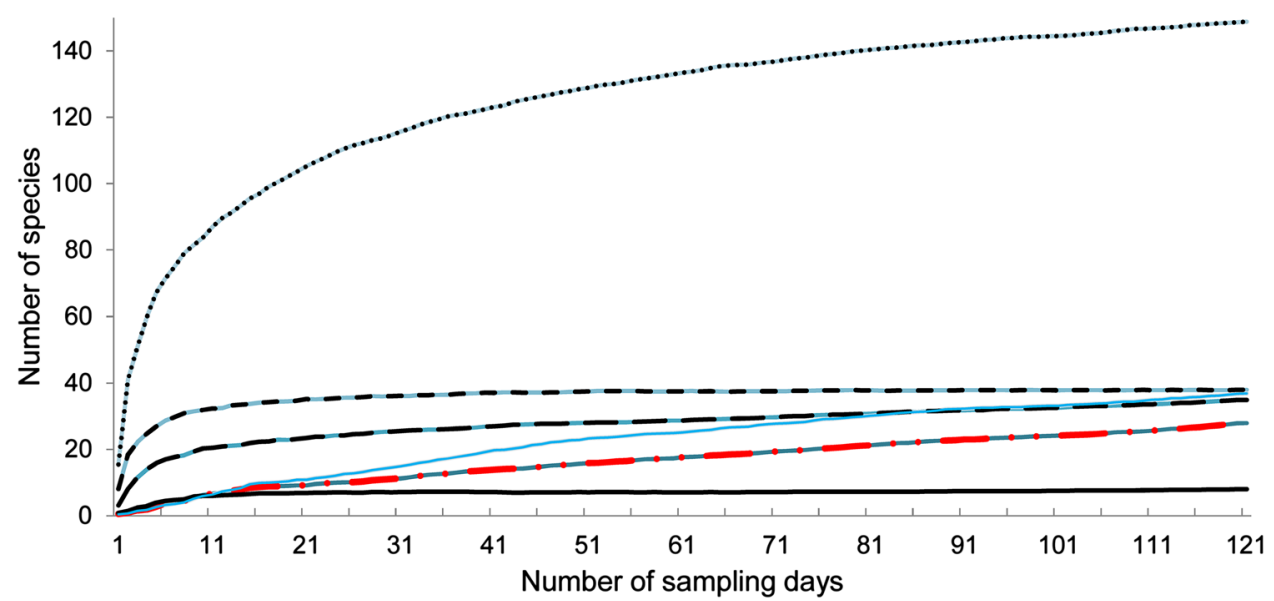

seasonality among butterflies that conclusions regarding the abundance and seasonality of specific species may be drawn (Online resource 1).

When comparing the checklist of butterflies recorded from Vietnam from 2003 to 2015 (Monastyrskii and Devyatkin 2003, 2015), the butterfly species known to Vietnam have increased dramatically from 992 species in 2003 to 1181 species in 2015. Intensified studies in the field together with taxonomic revisions have contributed to the recent high increase in species numbers. Several species have also been described new to science from areas close to our study area (Uehara and Yokochi 2001; Morita 2002, 2003; Seki and Saito 2006; Yokochi 2010, 2011, 2012). At least seven species (Euthalia bunzoi, E. iva, E. pyrrha, E. khambounei, E. bellula, E. masaokai and Dacalana inorthodoxa) that we recorded have been described new to science since 2000 (Yokochi 2011; Monastyrskii 2012; Monastyrskii and Devyatkin 2015). Euthalia monbeigi and E. masaokai were recorded for the first time in Vietnam in this study and we could not identify two specimens to any described species. This is surprisingly given that many expeditions have searched for new and rare butterflies in Lao Cai province and surrounding areas in China (Chou 1994; Hill and Monastyrskii 1999; Vu et al. 2015). Some individuals from the genus Eurema, Euthalia, Neptis, and Tajuria, remained difficult to identify to species level although they were collected and literature and butterfly experts were consulted (Online Resource 1, 2). For instance, Euthalia is a species rich genus that deserves further investigation in the region and a taxonomic revision is impending (Takashi Yokochi pers. comm.). The study area with high elevational differences and species from the two biogeographic ecozones Palearctic and Indomalaya, might still harbour unknown butterfly taxa (Monastyrskii 2007a).

Many previous studies of butterflies in Vietnam inevitably recorded much lower species richness compared to our study as they were based on lower sampling intensity (Leps and Spitzer 1990; Spitzer et al. 1993, 1997; Hill and Monastyrskii 1999; Vu and Yuan 2003; Monastyrskii 2007a; Vu 2009, 2011; Vu et al. 2015). Very intense studies in Northern Vietnam of Cuc Phuong National Park from 1995 until 1999 revealed 150 species (excluding Lycaenidae and Hesperiidae) (Ikeda et al. 2002) and 147 species over a 5-year study in Tam Dao National Park (Vu et al. 
2015). In 1998 Tordoff et al. (1999) recorded 199 butterfly species in Hoàng Liên National Park along 24 transects ranging in altitude from 1000 to $2550 \mathrm{~m}$. In our study, we recorded 231 species (191 excluding Lycaenidae and Hesperiidae) and this is a higher number than any other study has reported from a relatively small study area that we are aware of in Vietnam. Compared to butterfly communities at lower altitudes in Vietnam there are distinct differences and members from many genera such as Byasa, Chilasa, Delias, Pontia, Ypthima, Limbusa, Chitoria, Sephisa, Hestina, and Dodona were found in our study but are absent at lower altitudes. (Ikeda et al. 2002; Monastyrskii 2007a, b).

Many species in Hoàng Liên National Park seem to have a very small spatial distribution and seem not to occur in our study area or be very rare here (Online Resource 1). Some characteristic butterfly species of Hoàng Liên mountain ridge such as members from the genus Aemona, Parasarpa, Limenitis, Neptis, Athyma, Tanaecia, and Cynitia (all Nymphalidae) were not found in our study (Monastyrskii and Hill 1998; Tordoff et al. 1999). Most likely, many absent species should have either preference for other habitats/altitudes than we covered in our study or occur in small local population sizes with a low detectability that seems to be a feature among many tropical butterflies (Spitzer et al. 1993; Walpole and Sheldon 1999; Bonebrake et al. 2010). In agreement with our species richness estimation many species from Lycaenidae and Hesperiidae are missing in our list but known from the region such as members from the genera Zephyrus (Lycaenidae) and Celaenorrhinus (Hesperiidae) (Monastyrskii and Hill 1998; Tordoff et al. 1999; Morita 2002).

\section{Abundance and seasonality}

Species richness and abundance patterns across the year depend on multiple factors such as climatic conditions, the availability of host plants and floral resources. These factors might also explain our findings regarding seasonality in butterfly populations in the region, with activity of some species peaking in specific months and surprisingly large differences in the composition of the whole butterfly community between consecutive months. For example, in September there are relatively high temperatures, low humidity and many hours of sunshine, which may explain the high butterfly abundance and species richness observed in this month. Our seasonal pattern is supported by previous studies suggesting strong seasonality among Vietnamese butterflies in different climatic zones (Monastyrskii 2007a; Vu and Vu 2015). The observed seasonality pattern may be driven largely by low temperatures during winter (late November-March) but also variations in life span, the availability of host plants and nectar for adult butterflies. It is known that the life span of adult butterflies varies considerable (Beck 2008), and this might influence detectability and season patterns. Timing of adult emergence is an adaptive trait that depends on climate, nectar availability, and host plant resources (Spitzer et al. 1993). Thus, seasonal factors, including variability in food resources for larvae and nectar availability, may strongly influence patterns of butterfly species richness and abundance in the area. During winter, temperatures can fall below freezing and from June to September temperatures and rainfall are reaching their maximum in the region (Fig. 2), resulting in peak flowering of many tree, shrub, and herb species (Suepa et al. 2016). The abundance of weed species adapted to rice paddies also peaks during the rainy season, providing additional food resources for butterfly species (personal observation). The flora of the region is especially rich in tree, shrub and herb species (Fried et al. 2017) with many floristic elements characteristic of temperate regions and a high proportion of epiphytic orchids (Rundel 1999) and shrubs such as Rhododendron spp. (Thin and Harder 1996). The forests include evergreen broadleaved trees, conifers and mixed conifer-broad leaved forest (Thin and Harder 1996; Averyanov et al. 2003), which may explain the high levels of butterfly diversity observed. Flowering events of some plant species coincide with patterns in the butterfly population, so we suggest that the peaks in observed butterfly activity in July and September reflect the high accessibility of flowering plants, despite the rather wet and humid conditions, in these months.

We found that numbers of many species in the area were very low. This might be due to their high mobility, small local population sizes or low detectability. Many Pieridae and Nymphalidae butterflies are also highly mobile (Stevens et al. 2010), and many species of these families were represented in our sample by few individuals which probably entered the study area from the surroundings. This is consistent with expectations of high degrees of exchange with species from the surroundings as there is an extremely rich variety of habitats and climatic zones, ranging from lowland habitats at 200 m.a.s.l. to mountain habitats at 2600 m.a.s.l., within just $10 \mathrm{~km}$ of the study area. Only on some days we observed many individuals of highly mobile species, which were probably visiting the study area temporarily, perhaps due to favourable weather conditions or dense local populations in the surroundings prompting dispersal events (Sparks et al. 2007; Stevens et al. 2010; Li et al. 2013). Other species, such as Teinopalpus imperialis, might naturally occur in small population sizes locally, as this and other rare species are declining and under threat due to their diet specialization and habitat fragmentation (Spitzer et al. 1993). Unpredictable weather events can also potentially reduce the size of butterfly populations. The study area was hit by severe storms and heavy rains from 1st to 14th June 2014, which might partially explain 
the low abundance of butterflies in June and early July (Fig. 4b). Although it is well known that weather influences butterfly and moth population sizes (Roy et al. 2001; Franzén and Nilsson 2012), we currently lack information about how extreme weather affects butterfly population dynamics in tropical and subtropical areas. However, it seems very likely that heavy rains and storms increase the mortality of caterpillars, pupae and adult butterflies. Measures of daily fluctuations in abundance are difficult to interpret, but it may be that highly mobile species that often are visiting flowers tend to vary most between days, resulting in high coefficients of variation in numbers of individuals observed per day such as Papilio doddsi, Lamproptera curius, and Vanessa indica. The dominance of males in our data also reflects well-known difficulties in observing females, relative to males, possibly because they hide during egg laying or because they naturally expose themselves less than males who are searching for females (Fromhage et al. 2016).

\section{Sampling requirements and butterfly monitoring}

Generally, large charismatic flower-visiting species (such as many in the Papilionidae family) are much more detectable than small, non-flower-visiting species. Accordingly, we detected almost all species in the area from the families Papilionidae, Pieridae, and Riodinidae (Fig. 7) and our species list includes all species that are considered to be common in northern Vietnam (Monastyrskii 2007a, b). Most species of Papilionidae, Pieridae, and Riodinidae were detected after about 10 sampling days. Detection of most Nymphalidae species required about 30 sampling days, and many members of the Lycaenidae and Hesperiidae families apparently remained undetected in the study, as their species richness curves did not level out even after 121 days of sampling. Lycaenidae and Hesperiidae are known to have low detectability because of their small size, localized appearance (Kery and Plattner 2007), and strong habitat preferences (Spitzer et al. 1993, 1997). We only recorded about $10 \%$ of the species known from Northern Vietnam from these two families (Table 1). A separate targeted study may be required to find all species in the area of these families, which are often excluded from ecological studies because they are so demanding to study in the wild (Spitzer et al. 1993).

\section{Conservation implications}

Only three species (Troides helena, T. aeacus, and Teinopalpus imperialis) are present on both the Convention on International Trade in Endangered Species of wild fauna and flora (CITES) and the Vietnamese Red List (Vat 2007). South East Asia has the highest relative rate of habitat loss and degradation in the humid tropics (Koh 2007; Venter et al. 2016), and it is urgent to extend the red data book and/ or develop new lists that highlight a number of narrow Vietnamese endemic butterflies that face a high anthropogenic pressure and declining populations (Leps and Spitzer 1990; Monastyrskii 2007a). Many South East Asian butterflies are endemic to the region and will face global extinction if current levels of deforestation and environmental change continue (Koh et al. 2004; Koh 2007). Hence, repeated surveys of species richness and abundance are vital for assessing the current status and trends of butterfly communities. There are also urgent needs to integrate butterflies into conservation programs and use their potential as indicator species of habitat degradation and land use intensity (Kremen 1992; Fleishman et al. 2005) and for assessing and prioritizing investments in conservation efforts (Bonebrake et al. 2010). Surprisingly, very few earlier studies have provided data that can be used to track responses of indicator taxa to environmental changes that are occurring at alarming rates across South East Asia (Hector et al. 2011; Lindenmayer et al. 2012). We hope that our study will provide useful baseline data for further studies on butterflies and their ecology in the context of environmental change in the region, and for conserving both butterfly habitats and the butterfly fauna of northern Vietnam.

Acknowledgements We thank the inhabitants of Ta Phin village that supported our study. Viktor Mátyás Farkas helped with the field work. Alexander L. Monastyrskii gave valuable comments on the manuscript and corrected misidentified taxa. Takashi Yokochi, Martin Wiemers, and Norbert Hirneisen helped with identification of problematic species. This study was partly funded by the LEGATO (Land-use intensity and Ecological Engineering-Assessment Tools for Risks and Opportunities in Irrigated Rice Based Production Systems; German Ministry of Research and Education BMBF Funding No. 01LL0917F) project (Settele et al. 2015), the Royal Swedish Academy of Sciences, and Magnus Bergvalls Foundation.

Open Access This article is distributed under the terms of the Creative Commons Attribution 4.0 International License (http:// creativecommons.org/licenses/by/4.0/), which permits unrestricted use, distribution, and reproduction in any medium, provided you give appropriate credit to the original author(s) and the source, provide a link to the Creative Commons license, and indicate if changes were made.

\section{References}

Averyanov LV, Ke Loc P, Tien Hiep N, Harder DK (2003) Phytogeographic review of Vietnam and adjacent areas of Eastern Indochina. Komarovia 3:1-83

Beck J (2008) Phylogenetic and ecological correlates with male adult life span of rainforest butterflies. Evol Ecol 22:507-517

Bonebrake TC, Ponisio LC, Boggs CL, Ehrlich PR (2010) More than just indicators: a review of tropical butterfly ecology and conservation. Biol Conserv 143:1831-1841

Bozano GC, Coutsis JG, Herman P, Allegrucci G, Cesaroni D, Sbordoni V (2016) Guide to the Butterflies of the Palearctic Region: 
Pieridae 3: Coliadinae: Rhodocerini, Euremini, Coliadini (Gonepteryx and others) \& Dismorpiinae (Leptidea). Omnes Artes, Milan

Chou I (1994) Monographia Rhopalocerorum Sinensium. Henan Scientific and Technological Publishing House, Zhengzhou

Colwell RK (2013) EstimateS: statistical estimation of species richness and shared species from samples. Version 9: user's guide and application. http://purl.oclc.org/estimates. Accessed 25 May 2016

D' Abrera B (1982) Butterflies of the oriental region. Hill House, Melbourne

Fleishman E, Mac Nally R, Murphy DD (2005) Relationships among non-native plants, diversity of plants and butterflies, and adequacy of spatial sampling. Biol J Linn Soc 85:157-166

Franzén M, Nilsson S (2012) Climate-dependent dispersal rates in metapopulations of burnet moths. J Insect Conserv 16:941-947

Fried O, Kühn I, Schrader J, Sinh NV, Bergmeier E (2017) Plant diversity and community composition of rice agroecosystems in Vietnam and the Philippines. Phytocoenologia. doi: 10.1127/ phyto/2017/0123

Fromhage L, Jennions M, Kokko H (2016) The evolution of sex roles in mate searching. Evol Int J Org Evol 70:617-624

Hayes L, Mann DJ, Monastyrskii AL, Lewis OT (2009) Rapid assessments of tropical dung beetle and butterfly assemblages: contrasting trends along a forest disturbance gradient. Insect Conserv Diver 2:194-203

Hector A, Fowler D, Nussbaum R, Weilenmann M, Walsh RPD (2011) The future of South East Asian rainforests in a changing landscape and climate. Introd Philos Trans R Soc B 366:3165-3167

Hill MJ, Monastyrskii AL (1999) Butterfly fauna of protected areas in North and central Vietnam; collections 1994-1997. Atalanta 29:185-208

Ikeda K, Nishimura M, Inagaki H (2002) Butterflies of Cuc Phuong National Park in Northern VietNam (6). Butterflies 32:34-38

Kery M, Plattner M (2007) Species richness estimation and determinants of species detectability in butterfly monitoring programmes. Ecol Entomol 32:53-61

Koh LP (2007) Impacts of land use change on South-East Asian forest butterflies: a review. J Appl Ecol 44:703-713

Koh LP, Sodhi NS, Brook BW (2004) Ecological correlates of extinction proneness in tropical butterflies. Conserv Biol 18:1571-1578

Koleff P, Gaston KJ, Lennon JJ (2003) Measuring beta diversity for presence-absence data. J Anim Ecol 72:367-382

Kremen C (1992) Assessing the Indicator properties of species assemblages for natural areas monitoring. Ecol App 2:203-217

Küppers PV (2015) Butterflies of the World, Part 44: Nymphalidae XXV: Kallima. Verlag Goecke \& Evers, Keltern

Laurance WF, Useche D, Shoo LP, Herzog SK, Kessler M, Escobar F, Brehm G, Axmacher JC, Chen IC, Gámez LA, Hietz P, Fiedler K, Pyrcz T, Wolf J, Merkord CL, Cardelus C, Marshall AR, Ah-Peng C, Aplet GH, del Coro Arizmendi M, Baker WJ, Barone J, Brühl CA, Bussmann RW, Cicuzza D, Eilu G, Favila ME, Hemp A, Hemp C, Homeier J, Hurtado J, Jankowski J, Kattán G, Kluge J, Krömer T, Lees DC, Lehnert M, Longino JT, Lovett J, Martin PH, Patterson BD, Pearson RG, Peh KSH, Richardson B, Richardson M, Samways MJ, Senbeta F, Smith TB, Utteridge TMA, Watkins JE, Wilson R, Williams SE, Thomas CD (2011) Global warming elevational ranges and the vulnerability of tropical biota. Biol Conserv 144:548-557

Leps J, Spitzer K (1990) Ecological determinants of butterfly communities (Lepidoptera Papilionoidea) in the Tam Dao mountains Vietnam. Acta Entomol Bohemos 87:182-194

Li XS, Zhang YL, Settele J, Franzen M, Schweiger O (2013) Longdistance dispersal and habitat use of the butterfly Byasa impediens in a fragmented subtropical forest. Insect Conserv Diver 6:170-178

Lindenmayer D, Cunningham S, Young A (2012) Land use intensification: effects on agriculture biodiversity and ecological processes. CSIRO Publishing, Clayton

Monastyrskii AL (2005) Butterflies of Vietnam: Nymphalidae: Satyrinae. Dolphin Media, Hanoi

Monastyrskii AL (2007a) Ecological and biogeographical characteristics of the butterfly fauna (Lepidoptera Rhopalocera) of Vietnam. Entomol Obozrenie 86:43-72

Monastyrskii AL (2007b) Butterflies of Vietnam: Papilionidae. Dolphin Media, Hanoi

Monastyrskii AL (2011) Butterflies of Vietnam: Nymphalidae: Danainae; Amathusiinae. Dolphin Media, Hanoi

Monastyrskii AL (2012) New taxa and new records of butterflies from Vietnam (4). Atalanta 43:156-164

Monastyrskii AL, Devyatkin AL (2003) Butterflies of Vietnam (an illustrated checklist). Dolphin, Hanoi

Monastyrskii AL, Devyatkin AL (2015) Butterflies of Vietnam (an illustrated checklist). Planorama Media, Vietnam

Monastyrskii AL, Hill MJ (1998) Butterfly Fauna of the Hoàng Liên Mountains Collections 1994 1995. In: Sobey RT (ed) Biodiversity value of Hoàng Liên Mountains \& Strategies for conservation proceedings of seminar \& workshop 7-9th December 1997. $\mathrm{Sa} \mathrm{Pa}$ Lao Cai province. Vietnam SEE Forest Research Programme, London, pp 22-29

Morita S (2002) Three new subspecies of genus Chrysozephyrus (Shirózu et Yamamoto 1956) from Sapa NVietnam (Lepidoptera: Lycaenidae). Futao 40:6-8

Morita S (2003) Eight new subspecies of Theclini (Lycaenidae) from China and Vietnam. Futao 42:8-13

Myers N, Mittermeier RA, Mittermeier CG, da Fonseca GAB, Kent J (2000) Biodiversity hotspots for conservation priorities. Nature 403:853-858

Nakamura N (2014) Distribution of Kallima inachus (Doyere[1840]) and related species (Lepidoptera Nymphalidae) in Indochina and adjacent regions with status alteration of Kallima inachus alicia Joicey \& Talbot 1921. Butterflies 66:22-39

New TR (1997) Butterfly conservation. Oxford University Press, Oxford

Petanidou T, Kallimanis AS, Tzanopoulos J, Sgardelis SP, Pantis JD (2008) Long-term observation of a pollination network: fluctuation in species and interactions relative invariance of network structure and implications for estimates of specialization. Ecol Lett 11:564-575

Pollard E (1977) A method for assessing changes in the abundance of butterflies. Biol Conserv 12:115-134

Root TL, Price JT, Hall KR, Schneider SH, Rosenzweig C, Pounds JA (2003) Fingerprints of global warming on wild animals and plants. Nature 421:57-60

Roy DB, Rothery P, Moss D, Pollard E, Thomas JA (2001) Butterfly numbers and weather: predicting historical trends in abundance and the future effects of climate change. J Anim Ecol 70:201-217

Rundel PW (1999) Conservation priorities in Indochina: WWF desk study Forest habitats in Lao PDR Cambodia and Vietnam. World Wide Fund for Nature Indochina Programme Office, Hanoi

Seki Y, Saito K (2006) Four new species of Lycaenidae from Vietnam (Lepidoptera: Lycaenidae). Butterflies 42:38-45

Settele J, Spangenberg JH, Heong KL, Burkhard B, Bustamante JV, Cabbigat J, Ho Van C, Escalada M, Grescho V, Le Huu H, Harpke A, Horgan FG, Hotes S, Jahn R, Kuehn I, Marquez L, Schaedler M, Tekken V, Vetterlein D, Villareal SB, Westphal C, Wiemers M (2015) Agricultural landscapes and ecosystem services in South-East Asia-the LEGATO-Project. Basic Appl Ecol 16:661-664 
Sodhi NS, Koh LP, Brook BW, Ng PKL (2004) Southeast Asian biodiversity: an impending disaster. Trends Ecol Evol 19:654-660

Sparks TH, Dennis RL, Croxton PJ, Cade M (2007) Increased migration of Lepidoptera linked to climate change. Eur J Entomol 104:139-143

Spitzer K, Novotny V, Tonner M, Leps J (1993) Habitat preferences distribution and seasonality of the butterflies (Lepidoptera Papilionoidea) in a montane tropical rain forest Vietnam. J Biogeogr 20:109-121

Spitzer K, Jaros J, Havelka J, Leps J (1997) Effect of small-scale disturbance on butterfly communities on an Indochinese montane rainforest. Biol Conserv 80:9-15

Stevens VM, Turlure C, Baguette M (2010) A meta-analysis of dispersal in butterflies. Biol Rev 85:625-642

Stott P (1991) Asian and Pacific ecology Asia and the Pacific (ed by RH Taylor). Facts on File, New York, pp 1555-1576

Suepa T, Qi J, Lawawirojwong S, Messina JP (2016) Understanding spatio-temporal variation of vegetation phenology and rainfall seasonality in the monsoon Southeast Asia. Environ Res 147:621-629

Suguru I, Haruo F (1997) The life histories of Asian butterflies. Tokai University Press, Tokyo

Suguru I, Haruo F (2000) The life histories of Asian butterflies. Tokai University Press, Tokyo

Thin NN, Harder DK (1996) Diversity of the flora of Fan Si Pan the highest mountain in Vietnam. Ann Mo Bot Gard 83:404-408

Tilman D, Fargione J, Wolff B, D'Antonio C, Dobson A, Howarth R, Schindler D, Schlesinger WH, Simberloff D, Swackhamer D (2001) Forecasting agriculturally driven global environmental change. Science 292:281-284

Tordoff A, Swan S, Grindley M, Siurua H (1999) Hoàng Liên Nature Reserve. Frontier-Vietnam Forest Research Programme Report No 13

Uehara J, Yokochi T (2001) Two new species of Euthalia (Lepidoptera Nymphalidae) from northern Laos and northern Vietnam. Trans Lepid Soc Japan 52:237-244

Vat PD (2007) Red data book of Vietnam, vol 1. Animals Science and Technics Publishing House, Hanoi
Venter O, Sanderson EW, Magrach A, Allan JR, Beher J, Jones KR, Possingham HP, Laurance WF, Wood P, Fekete BM, Levy MA, Watson JEM (2016) Sixteen years of change in the global terrestrial human footprint and implications for biodiversity conservation. Nat Commun. doi:10.1038/ncomms 12558

Vu VL (2009) Diversity and similarity of butterfly communities in five different habitat types at Tam Dao National Park. Vietnam J Zool 277:1-333

$\mathrm{Vu}$ VL (2011) Diversity of butterflies in a tropical rain forest of Van Ban Nature Reserve Lao Cai Province Vietnam (Lepidoptera: Rhopalocera). Russ Entom J 20:411-418

Vu QC, Vu VL (2015) Seasonal dynamics of butterfly (Lepidoptera Rhopalocera) abundance in the Tropical Rain Forest of Vietnam. Entomol Rev 95:578-582

Vu VL, Yuan D (2003) The differences of butterfly (Lepidoptera Papilionoidea) communities in habitats with various degrees of disturbance and altitudes in tropical forests of Vietnam. Biodiv Conserv 12:1099-1111

Vu VL, Bonebrake TC, Vu MQ, Nguyen NT (2015) Butterfly diversity and habitat variation in a disturbed forest in northern Vietnam. Pan-Pac Entomol 91:29-38

Walpole MJ, Sheldon IR (1999) Sampling butterflies in tropical rainforest: an evaluation of a transect walk method. Biol Conserv 87:85-91

Wolda H (1988) Insect seasonality why? Annu Rev Ecol Syst 19:1-18

Yokochi T (2010) Revision of the Subgenus Limbusa Moore [1897] (Lepidoptera Nymphalidae Adoliadini). Part 1 Systematic arrangement and taxonomic list. Bull Kitakyushu Mus Nat Hist Hum Hist Ser A 8:19-67

Yokochi T (2011) Revision of the Subgenus Limbusa Moore[1897] (Lepidoptera Nymphalidae Adoliadini). Part 2 Group division and descriptions of species (1). Bull Kitakyushu Mus Nat Hist Hum Hist ser A 9:9-106

Yokochi T (2012) Revision of the Subgenus Limbusa Moore [1897] (Lepidoptera Nymphalidae Adoliadini). Part 3 Group division and descriptions of species (2). Bull Kitakyushu Mus Nat Hist Hum Hist Ser A 10:9-100 